\title{
Mössbauer and magnetization studies of nanosize chromium ferrite
}

\author{
Brajesh Pandey
}

Department of Physics, I.I.T. Kanpur 208016, INDIA

Email: bpandey@gmail.com

\begin{abstract}
Nanosize chromium ferrite $(\mathrm{CrF})$ powder samples were synthesized by citrate precursor route in the size range of 6 to $35 \mathrm{~nm}$. The structural and magnetic behaviour of these samples were studied using X-ray diffraction (XRD), vibrating sample magnetometer (VSM) and Mössbauer spectroscopic techniques. Synthesized chromium ferrite powders were in good phase and showed spinel structure in the XRD pattern. Nanocrystalline CrF powder samples interact with the laboratory magnet strongly and show large magnetization in the VSM measurement. In these CrF samples, maximum magnetization sensitively depends on the particle size of synthesized powders. We observed about $12 \mathrm{~A}-\mathrm{m}^{2} / \mathrm{kg}$ of magnetization in $35 \mathrm{~nm}$ chromium ferrite samples. In spite of this much magnetization in the chromium ferrite nanoparticles, no hyperfine splitting was observed even down to a temperature $16 \mathrm{~K}$.
\end{abstract}

Keywords: Mössbauer spectroscopy, Ferrites, nanophase iron, magnetic nanoparticles.

\section{Introduction}

Nanosize ferrites prepared by a variety of methods have been studied by large number of researchers in the past decade (Ho et al., 1995; Hamdeh et al., 1997; Jiang et al., 1999; Oliver et al., 1999; Zhou et al., 2001; Kundu et al., 2003; Tada et al., 2003). The most interesting aspect in several nanosize ferrites is the cation distribution where increasing degree of inversion is found conclusively with decreasing particle size. This leads to enhanced magnetization in the otherwise paramagnetic system.

Hyperfine magnetic field at the site of ${ }^{57} \mathrm{Fe}$ nucleus is supposed to come from the exchange coupled magnetic ions and this itself is responsible to magnetic ordering in the crystalline system and gives rise to magnetization. Thus, magnetization $\mathrm{M}_{\mathrm{s}}$ and hyperfine magnetic field $\mathrm{B}_{\mathrm{hf}}$ go hand in hand and it is often assumed that $\mathrm{B}_{\mathrm{hf}}$ is proportional to $\mathrm{M}_{\mathrm{s}}$.

Iron, chromium and oxygen form a stable oxide $\mathrm{FeCr}_{2} \mathrm{O}_{4}$ known as iron chromite. This system too is paramagnetic and gives a single line in Mössbauer spectrum corresponding to $\mathrm{Fe}^{2+}$ state in A-site. We prepared $\mathrm{Fe}$-Cr oxide by forcing much more $\mathrm{Fe}$ in the system to have $\mathrm{Fe} / \mathrm{Cr}$ atomic ratio 2 instead of 0.5. It was shown by Robbins et al. (1971) that in iron rich $\mathrm{Fe}_{1+\mathrm{x}} \mathrm{Cr}_{2-\mathrm{x}} \mathrm{O}_{4}$ all the additional iron goes as $\mathrm{Fe}^{3+}$ in $\mathrm{B}$-site up to $\mathrm{x}<0.68$ making the composition $\left(\mathrm{Fe}^{2+}\right)\left[\mathrm{Cr}_{2-x} \mathrm{Fe}_{x}^{3+}\right] \mathrm{O}_{4}$. As more iron is substituted, up to $\mathrm{x}<1.38$, the substituted iron goes as $\mathrm{Fe}^{3+}$ into A-site displacing corresponding amount of $\mathrm{Fe}^{2+}$ ions to $\mathrm{B}$-site. For further increase of $\mathrm{x}(\mathrm{x}>1.38) \mathrm{B}$-sites tends to have equal amount of $\mathrm{Fe}^{3+}$ and $\mathrm{Fe}^{2+}$ ions. The Mössbauer spectrum shows up a six-line pattern only for $\mathrm{x}>1.38$ when $\mathrm{Fe}^{3+}$ ions at $\mathrm{A}$ and $\mathrm{B}$ sites interact via oxygen ions. The Mössbauer spectrum of $\mathrm{Fe}_{2} \mathrm{CrO}_{4}$ can therefore be expected to be composed for several doublets corresponding to $\mathrm{Fe}^{2+}$ and $\mathrm{Fe}^{3+}$ in $\mathrm{A}$ and $\mathrm{B}$ sites of spinel structure of iron-chromite. Thus, this is a spinel system in which both the cations have magnetic moments, still the Mössbauer spectra show lack of hyperfine field $\mathrm{B}_{\mathrm{hf}}$. We would like to see if this system shows significant magnetic ordering in the magnetization measurements.

\section{Materials and Methods}

Nanosize chromium ferrites in the size range of 6 to $35 \mathrm{~nm}$ were synthesized by taking aqueous solutions of citrate salts. To make chromium ferrite, iron and chromium citrate solutions with citric acid were taken such that cations to citric acid ratio become 1:3. This aqueous solution was refluxed for $24 \mathrm{~h}$ and then dried at $90{ }^{\circ} \mathrm{C}$ to obtain the precursor. This precursor was calcined in 
open air at various temperatures between $300{ }^{0} \mathrm{C}-700{ }^{0} \mathrm{C}$ for 1 hour to obtain $\mathrm{Cr}$-ferrite $(\mathrm{CrF})$ of the required particle size. The chemicals used in the preparation of these ferrites were from Loba Chemie, India make and had GR grade purity.

The crystallographic structure, phase formed and crystallite size of the prepared powder samples were characterized by XRD using $\mathrm{Cu}-\mathrm{K}_{\alpha}$ radiation. The XRD spectra of the samples were recorded with SEIFERT ISO DEBYEFLEX 2002 under identical conditions to minimize the experimental errors in the quantitative analysis of crystallite size and crystallinity. The microstructures of the samples were obtained by a transmission electron microscope (TEM) of JEOL, JEM-200CX model. The powder was dispersed in methanol and ultrasonicated for around 15 minutes. A drop of this well dispersed dilute suspension was put on a carbon coated grid (normally $3 \mathrm{~mm}$ diameter with suitable mesh size) obtained from Palco ltd. USA.

About $25 \mathrm{mg}$ of powder sample was wrapped in a Teflon tape and subjected to Vibrating Sample Magnetometer (VSM) to study the magnetization behaviour. The maximum applied magnetic field in the VSM experiment was $1.25 \mathrm{~T}$ in either direction at room temperature. Mössbauer spectroscopy was used to elucidate the local structure and magnetic properties of the samples through the hyperfine interactions. Mössbauer spectra were recorded at room temperature and down to $16 \mathrm{~K}$ in a transmission geometry using a conventional ${ }^{57} \mathrm{Fe}$ constant acceleration Mössbauer spectrometer employing a $25 \mathrm{mCi}{ }^{57} \mathrm{Co} / \mathrm{Rh}$ source. The spectra were analyzed using least squares method assuming Lorenzian line shapes. The isomer shift (IS) and quadrupole splitting (QS) have an uncertainty of about $0.02 \mathrm{~mm} / \mathrm{s}$. Relative areas are accurate up to $2 \%$.

\section{Results and discussions}

\subsection{X-Ray Diffraction}

Figure 1 show typical X-ray diffraction patterns of $6 \mathrm{~nm}, 13 \mathrm{~nm}$ and $35 \mathrm{~nm}$ size CrF samples. All the peaks in the XRD pattern of these samples can be identified to come from the spinel structure like $\mathrm{ZnFe}_{2} \mathrm{O}_{4}$ showing that the samples are formed in pure spinel phase. Background of XRD pattern is smooth in samples having bigger particles size, but as particle size decreases background fluctuation increased. This could be because in smaller particles sample defect density is very high due to more broken bonds present at surface and these offers more scattering centres.

The peak positions of the XRD pattern of all $\mathrm{CrF}$ samples synthesized are well matched with the positions of the spinel structure. From the peak broadening of the XRD patterns the average particle size using Scherrer formula was estimated as a function of calcination temperature of precursor. Figure 2 shows the variation of particle size with calcination temperature. Particle size reported in Figure 2 has an uncertainty of $0.5 \mathrm{~nm}$.

\subsection{Strain analysis}

Apart from the smaller crystallite size, crystal strains too contribute towards broadening of XRD peaks. To separate the effect of size and strain Williamson-Hall (W-H) plot (Williamson and Hall, 1953; Pandey, 2007] is useful. In this method, the XRD peak broadening can be split in two parts according to following equation

$$
\beta=\beta_{\text {Size }}+\beta_{\text {Strain }}
$$

The actual sample peak broadening can be obtained by correcting the experimental peak broadening as, $\beta^{2}=\beta_{\mathrm{p}}{ }^{2}-\beta_{\mathrm{R}}{ }^{2}$; where $\beta_{\mathrm{p}}$ is the observed full width at half maximum (FWHM) with the sample and $\beta_{\mathrm{R}}$ is the FWHM of the peak of a well crystalline reference material with crystallite size greater than $100 \mathrm{~nm}$

Hence, one can rewrite equation (1) as

$$
\begin{aligned}
& \beta=\frac{0.9 \lambda}{t \cos \theta}+\frac{4(\Delta d) \sin \theta}{d \cos \theta} \\
& \beta \cos \theta=\frac{0.9 \lambda}{t}+\left(\frac{\Delta d}{d}\right) 4 \sin \theta
\end{aligned}
$$

The slop of the plot $\beta \cos \theta$ Vs $4 \sin \theta$ gives the $\operatorname{strain}\left(\frac{\Delta d}{d}\right)$ and from the intercept one can estimate the particle/crystalline size.

Figure 3 shows W-H plot of all CrF samples. From the intercept corresponding to each sample, the particle size was calculated. It is worth to mention here that the particle size calculated by intercepts is in good agreement with those calculated by Scherrer formula within the experimental limit of $0.5 \mathrm{~nm}$.

W-H plot of $11 \mathrm{~nm}$ size CrF shows very high slop which indicates that at this size strain is very high. Figure 4 shows the variation of strain with particle size. The strain increases very rapidly up to $11 \mathrm{~nm}$ of particle size and then decreases. From the 
strain analysis it is clear that the physical properties may be very interesting in the samples having particles smaller and bigger than 11-12 nm size. It may possible that this behaviour of strain plays an important role in determining physical properties.
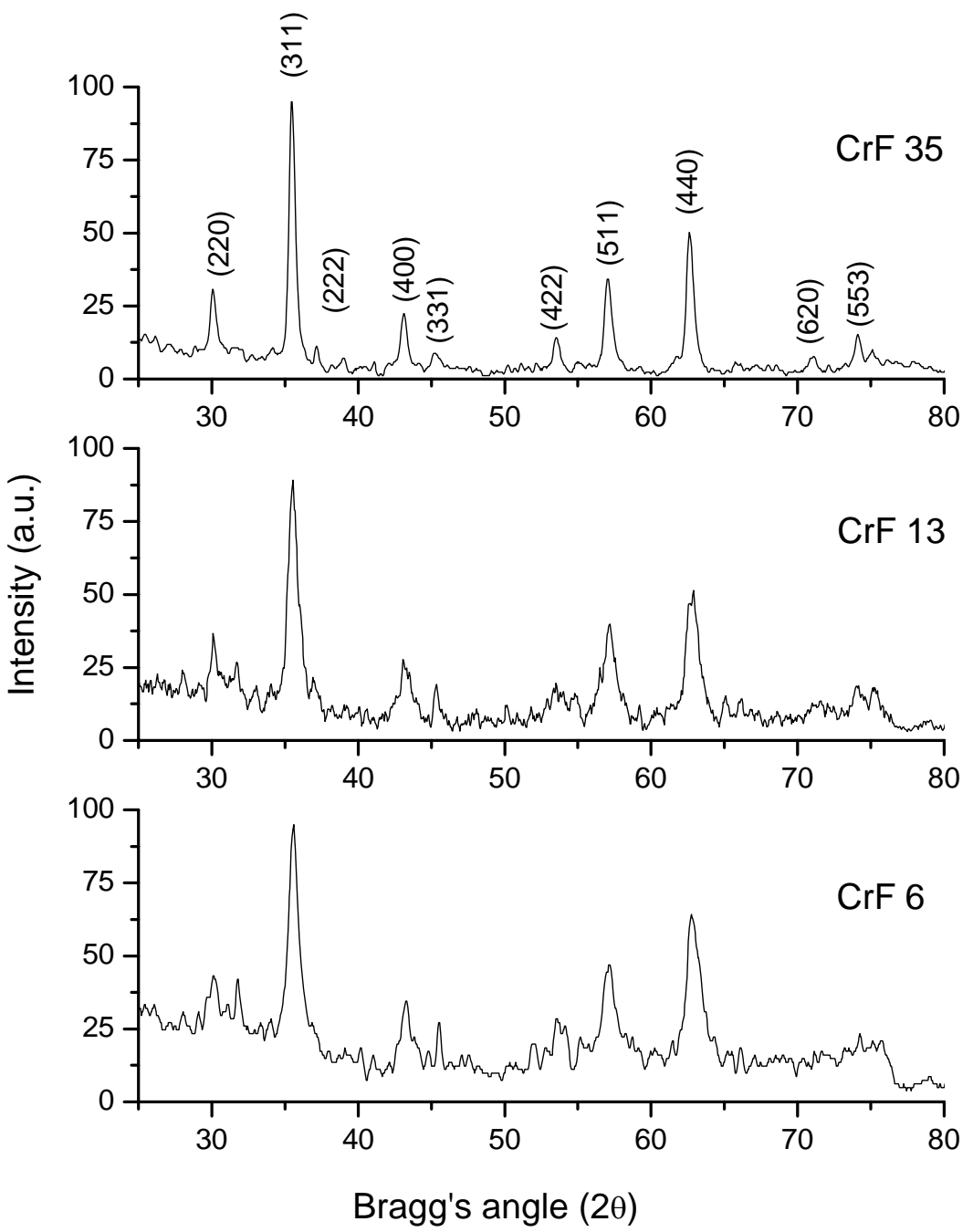

Figure 1: XRD pattern of $6 \mathrm{~nm}, 13 \mathrm{~nm}$ and $35 \mathrm{~nm}$ size $\mathrm{CrF}$ nanoparticles 


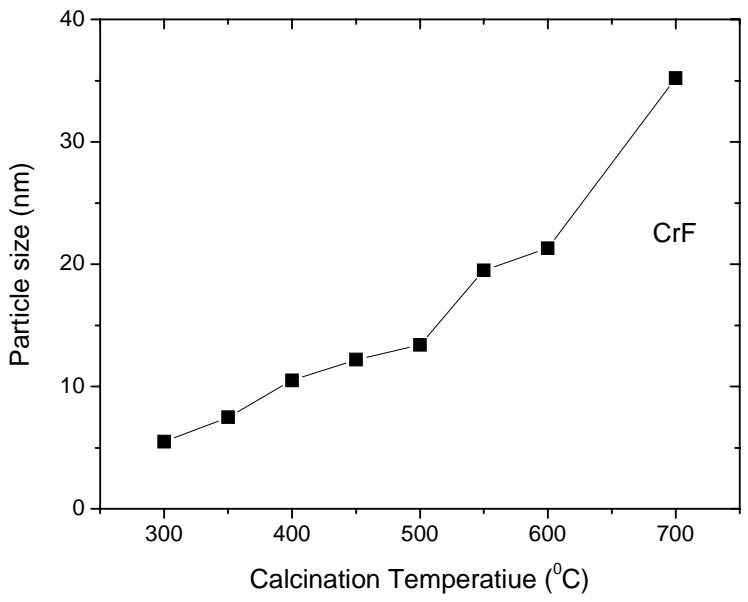

Figure 2: Variation of particle size of $\mathrm{CrF}$ with the calcination temperature

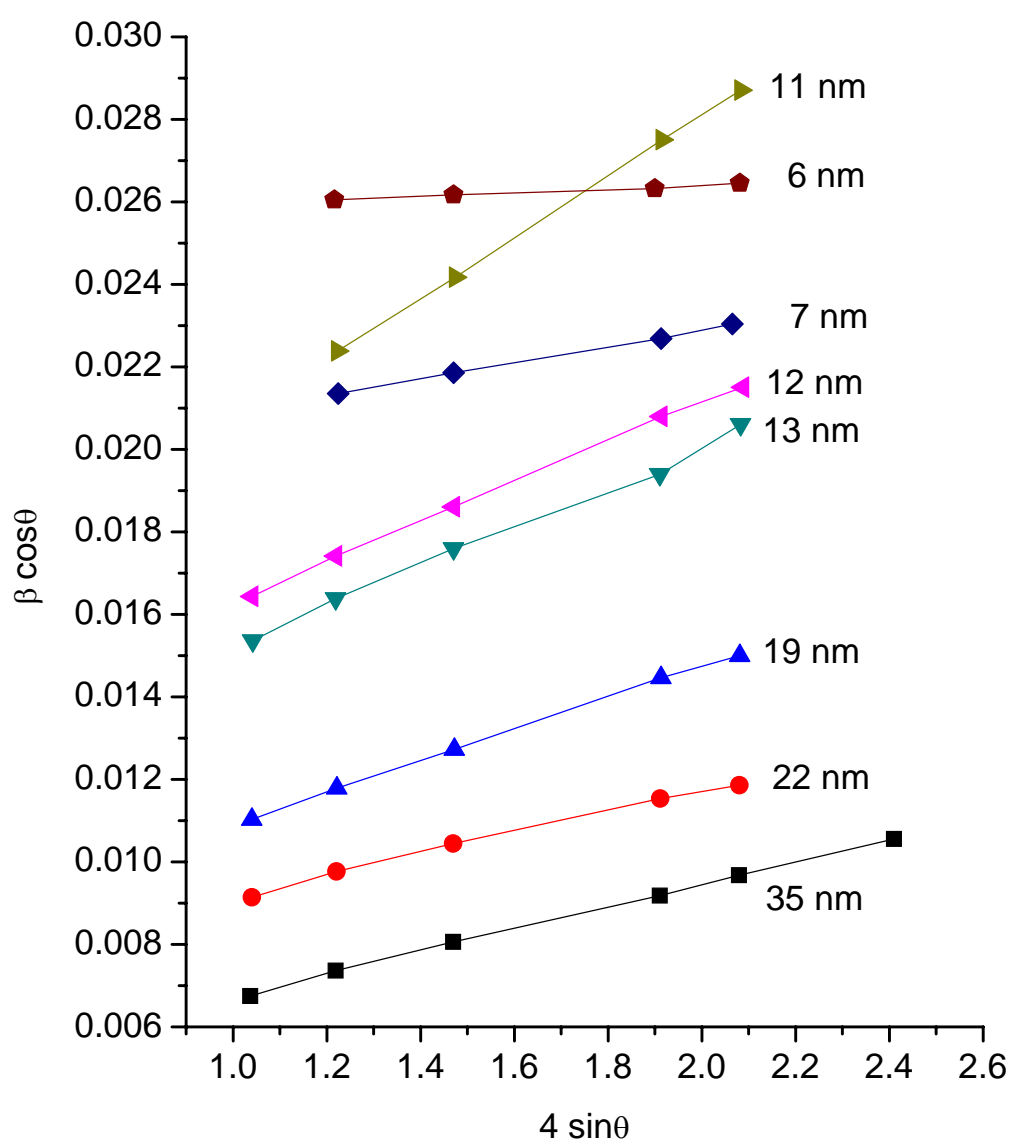

Figure 3: W-H Plot of CrF nanoparticles. Lines are drawn to guide the eyes. 


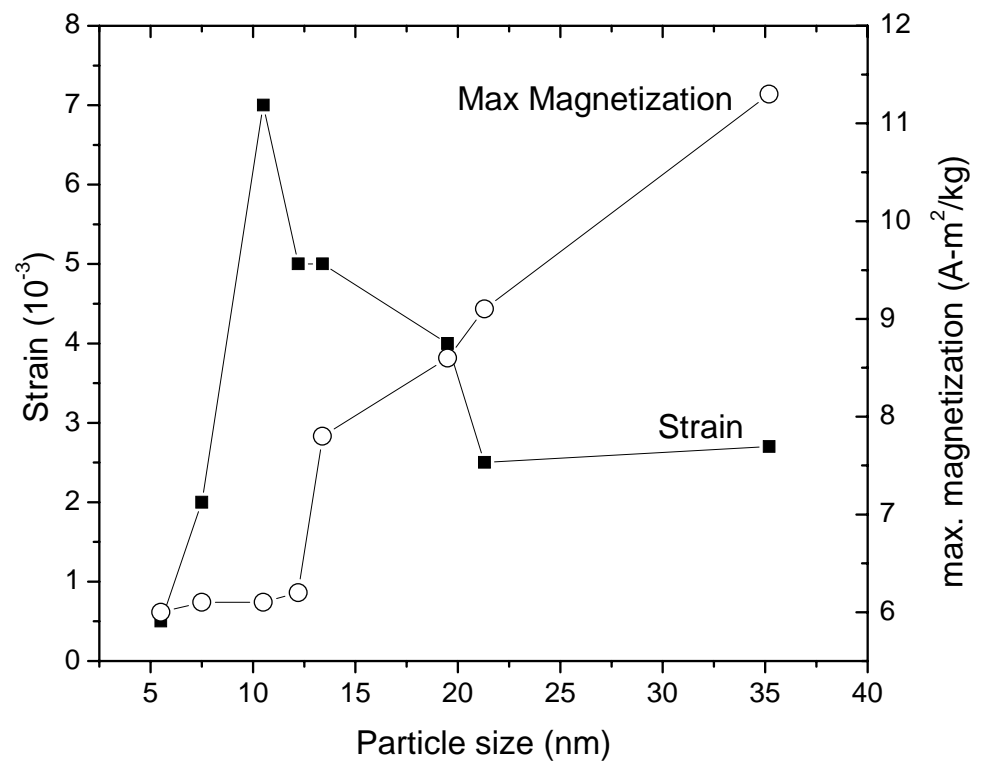

Figure 4: Variation of strain and maximum magnetization of $\mathrm{CrF}$ nanoparticles with particle size

\subsection{TEM Micrograph}

Figure 5 shows typical TEM micrograph of $11 \mathrm{~nm}$ CrF sample. The sample of $11 \mathrm{~nm}$ has been chosen because it shows very high strain. As discussed in the above section, this sample is showing very high strain. So in $11 \mathrm{~nm} \mathrm{CrF}$, the distribution of particle size should be more. TEM micrograph shows that the particles are formed in a controlled manner and the variation in the size of their particles is very small. As we have mentioned in section 3.1, the uncertainty in the calculation of particle size is around 0.5 $\mathrm{nm}$. TEM micrographs are also supporting our observations that particle size distribution is very fine. Here, a typical TEM micrograph has been given because others are similar to that of $11 \mathrm{~nm}$ as for as visual appearance is concerned at different resolution.

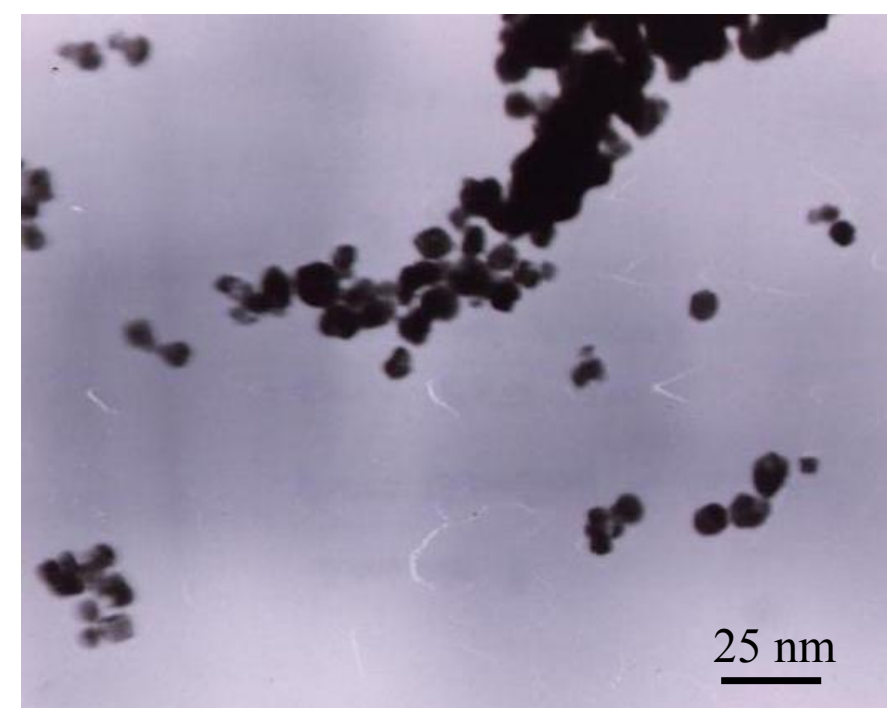

Figure 5: Typical TEM micrograph of $11 \mathrm{~nm}$ particle size $\mathrm{CrF}$ sample 


\subsection{Magnetization studies}

To get an idea of magnetization in pure spinel structure it is fruitful to mention the following. Magnetization in the ferrite samples prepared by different chemical routes strongly depends on the preparation route chosen. For example, Kundu et al. (2003a) prepared $\mathrm{ZnFe}_{2} \mathrm{O}_{4}$ of size $13 \mathrm{~nm}$ using a relatively less common co-precipitation technique, using urea hydrolysis for few minutes and reported magnetization of about $21 \mathrm{Am}^{2} / \mathrm{kg}$ at $1.07 \mathrm{~T}$ of external applied field. Shenoy et al. (2004) prepared $\mathrm{ZnFe}_{2} \mathrm{O}_{4}$ nanosize particles using co-precipitation technique followed by ball milling, and found saturation magnetization around 7.5 $\mathrm{Am}^{2} / \mathrm{kg}$ for $9 \mathrm{~nm}$ particles. Chinnasamy et al. (2000) prepared nanosize $\mathrm{ZnFe}_{2} \mathrm{O}_{4}$ particles of different sizes using high energy ball milling and found saturation magnetization around $11 \mathrm{Am}^{2} / \mathrm{kg}$ for particles of $11 \mathrm{~nm}$ size. The $\mathrm{ZnFe}_{2} \mathrm{O}_{4}$ nanoparticles prepared by taking nitrate salts [Roy et al., 2006] of constituent elements have shown the maximum magnetization of $13.4 \mathrm{Am}^{2} / \mathrm{kg}$ for the $6 \mathrm{~nm}$ of $\mathrm{ZnFe}_{2} \mathrm{O}_{4}$ nanoparticles.

The VSM measurement shows that all the samples have similar behaviour of $\mathrm{M}-\mathrm{H}$ curve expected for the maximum magnetization. Typical M-H curves of 6, 13 and $35 \mathrm{~nm} \mathrm{CrF}$ are shown in Figure 6. These samples show a typical S-type shape, though the coercive force is very small. The magnetization rises very sharply as the applied field increases from zero in either direction and then slowly approaches saturation. This is typical behaviour of nanosize magnetic material where residual superparamagnetic relaxation leads to slow rise in the wings and ferri/ferromagnetic part contributes to hysteresis loop with small coercive field. As we know in zinc ferrite the magnetization appears due to cationic inversion at smaller particle size. In $\mathrm{CrF}$ samples, the situation is different, both $\mathrm{Fe}$ and $\mathrm{Cr}$ have magnetic moment and therefore can form magnetic domains. At smaller particle size, the bonds are broken and the magnetic coupling becomes weak. The variation of maximum magnetization produced in $\mathrm{CrF}$ with the particle size is shown in Figure 4.

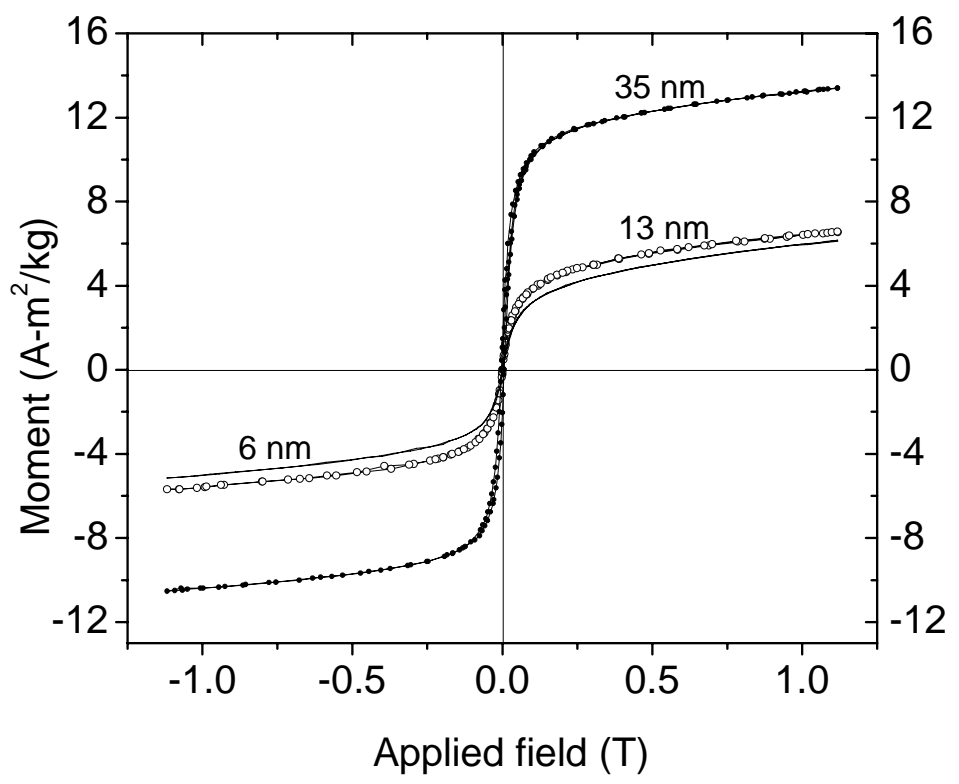

Figure 6: Typical M-H curve of $6 \mathrm{~nm}, 13 \mathrm{~nm}$ and $35 \mathrm{~nm} \mathrm{CrF}$ in an applied field of up to $1.25 \mathrm{~T}$

The maximum magnetization at $1.25 \mathrm{~T}$ for the $35 \mathrm{~nm} \mathrm{CrF}$ is $12 \mathrm{Am}^{2} / \mathrm{kg}$, which is quite high for an otherwise paramagnetic system. This shows that $35 \mathrm{~nm}$ sample has a ferrimagnetic ordering. This implies that at $35 \mathrm{~nm}$ size, there must be iron present at A and B -sites setting in A-O-B super-exchange. It has been observed that powders of size 11-12 nm or smaller are strongly attracted by the laboratory hand magnet and gives the maximum magnetization of $6.2 \mathrm{Am}^{2} / \mathrm{kg}$ only.

Figure 4 shows that the maximum magnetization is very small for samples of particles size 6, 7, 11 and $12 \mathrm{~nm}$. While it sharply increases after $12 \mathrm{~nm}$ of size. We have mentioned in previous section that strain in the samples can not be ignored. So, we can say that 11-12 nm particle size is critical size in $\mathrm{CrF}$ samples to alter magnetic properties. We can propose here that in the smaller particle size samples very small numbers of magnetic domains are formed and hence showing low magnetization. Further experiments are needed to investigate the relational ship between strain and other properties of $\mathrm{CrF}$. 


\subsection{Mössbauer Spectroscopy}

In order to look for the possibility of having magnetic ordering but no hyperfine magnetic field, Mössbauer spectra of all synthesized samples were recorded. $50 \mathrm{mg}$ each of powder samples was put in copper ring of diameter $13 \mathrm{~mm}$ and was fixed with cellophane tape which served as Mössbauer absorber. $50 \mathrm{mg}$ of samples contain around $18.0 \pm 0.5 \mathrm{mg} / \mathrm{cm}^{2}$ iron in the absorber ring. Figure 6 show Mössbauer spectra of $6 \mathrm{~nm}$ [Figure 6 (a)], $13 \mathrm{~nm}$ [Figure 6 (b)] and $35 \mathrm{~nm}$ [Figure 6 (c)] CrF samples at room temperature. All of them are showing a single doublet and no sign of any six-line pattern even down to $16 \mathrm{~K}$ [Figure 6 (d)]. Other samples also showed similar behaviour at room temperature and at $16 \mathrm{~K}$ too. For $13 \mathrm{~nm}$ sample isomer shift (IS) slightly increased from $0.31 \mathrm{~mm} / \mathrm{s}$ to $0.39 \mathrm{~mm} / \mathrm{s}$ as we go down to $16 \mathrm{~K}$ from room temperature while there is no appreciable change in quadrupole splitting (QS). Table 1 shows the Mössbauer parameters of all CrF samples at room temperature as well as at $16 \mathrm{~K}$. From table it is clear that for other samples the parameters are almost similar where they show slight increase in IS but no change in QS as going down to $16 \mathrm{~K}$. Thus, despite having considerable magnetic ordering shown in magnetization measurement these samples show no hyperfine magnetic field. One can interpret this effect by assuming that for the smaller particle size samples the total magnetic moment of an individual particle is small as the size is small (the particles are essentially single domain particles at this size) and will fluctuate during the thermal motion. Due to this superparamagnetic relaxation, the effective $\mathrm{B}_{\mathrm{hf}}$ will be zero. But when put in a strong magnetic field, the magnetic field will align them and this will show a considerable magnetization. This also explains why they get attracted by the magnet.

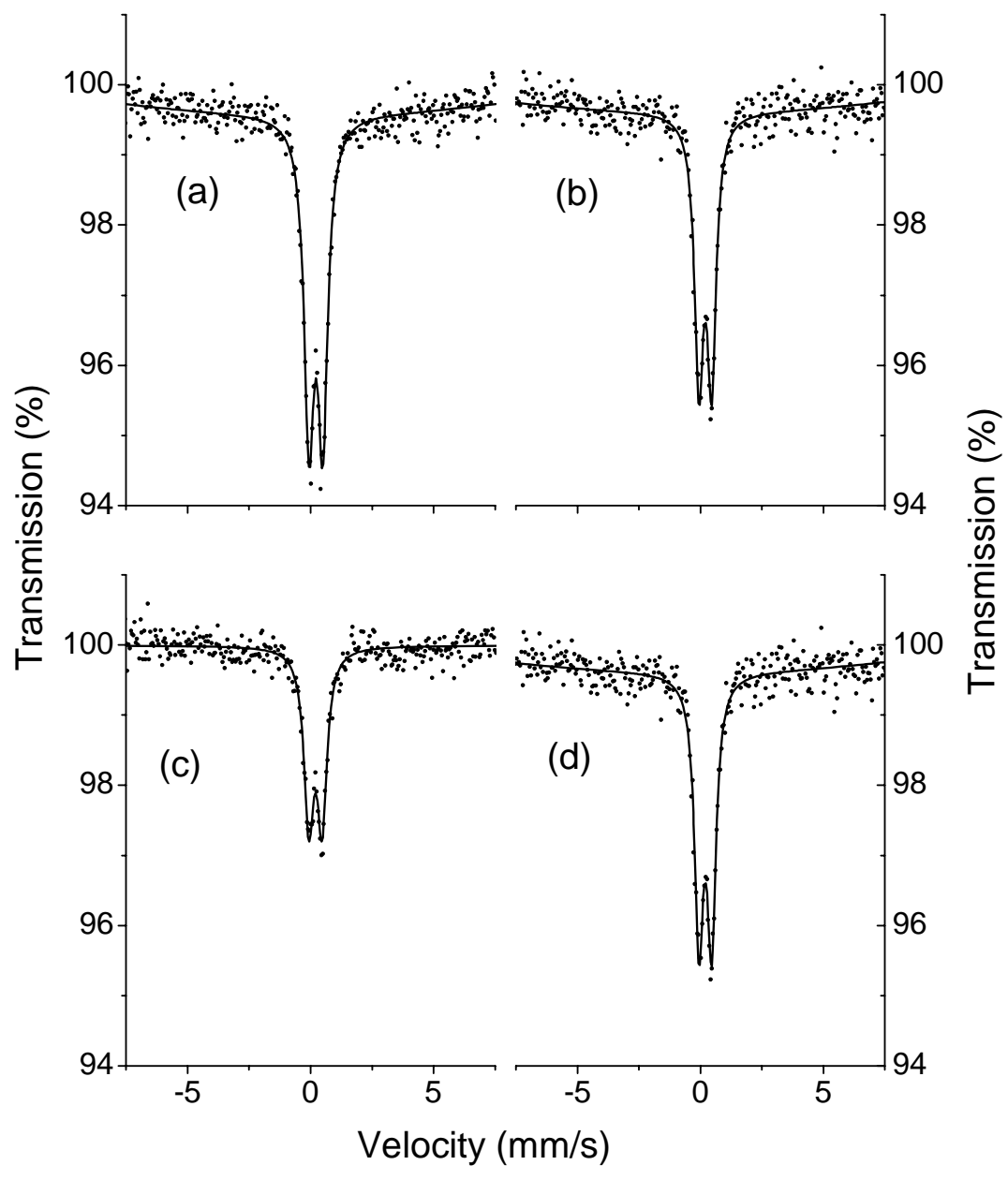

Figure 7: Mössbauer spectra of nanosize CrF samples (a) $6 \mathrm{~nm}$, (b) $13 \mathrm{~nm}$ and (c) $35 \mathrm{~nm}$ at room temperature and (d) $13 \mathrm{~nm}$ at $16 \mathrm{~K}$ 
Table1: Mössbauer parameter of CrF samples. Isomer shift (IS), quadrupole splitting (QS) and line-width $(\Gamma)$ has and uncertainty of $0.04 \mathrm{~mm} / \mathrm{s}$. RT stands for Room Temperature.

\begin{tabular}{lllll}
\hline & Temp & IS $(\mathrm{mm} / \mathrm{s})$ & QS $(\mathrm{mm} / \mathrm{s})$ & $\Gamma(\mathrm{mm} / \mathrm{s})$ \\
\hline $6 \mathrm{~nm}$ & RT & 0.31 & 0.56 & 0.49 \\
& $16 \mathrm{~K}$ & 0.40 & 0.55 & 0.54 \\
$7 \mathrm{~nm}$ & RT & 0.31 & 0.56 & 0.50 \\
& $16 \mathrm{~K}$ & 0.39 & 0.55 & 0.53 \\
$11 \mathrm{~nm}$ & RT & 0.31 & 0.56 & 0.51 \\
& $16 \mathrm{~K}$ & 0.39 & 0.56 & 0.53 \\
$12 \mathrm{~nm}$ & RT & 0.29 & 0.54 & 0.45 \\
& $16 \mathrm{~K}$ & 0.38 & 0.53 & 0.48 \\
$13 \mathrm{~nm}$ & RT & 0.29 & 0.52 & 0.44 \\
& $16 \mathrm{~K}$ & 0.38 & 0.52 & 0.47 \\
$19 \mathrm{~nm}$ & RT & 0.29 & 0.51 & 0.45 \\
& $16 \mathrm{~K}$ & 0.38 & 0.52 & 0.49 \\
$22 \mathrm{~nm}$ & RT & 0.28 & 0.52 & 0.45 \\
& $16 \mathrm{~K}$ & 0.38 & 0.53 & 0.49 \\
$35 \mathrm{~nm}$ & RT & 0.31 & 0.56 & 0.46 \\
& $16 \mathrm{~K}$ & 0.39 & 0.57 & 0.51 \\
\hline
\end{tabular}

Another interesting observation about $\mathrm{CrF}$ sample is that it has no trace of $\mathrm{Fe}^{2+}$ state. As mentioned earlier all the iron in $\mathrm{Fe}^{2+} \mathrm{Cr}_{2-x} \mathrm{Fe}_{x}^{3+} \mathrm{O}_{4}$ for $\mathrm{x}=0$ goes in $\mathrm{Fe}^{2+}$ state and only additional iron goes in $\mathrm{Fe}^{3+}$ state as $\mathrm{x}$ is increased. Thus, one should expect almost equal contributions from $\mathrm{Fe}^{2+}$ and $\mathrm{Fe}^{3+}$ states in a sample $\mathrm{Fe}_{2} \mathrm{CrO}_{4}$. With both $\mathrm{Fe}$ and $\mathrm{Cr}$ in $3+$ state, for charge balance, cationic vacancies are expected and in such a samples the iron bonding may be weak.

Coming to the main observation, it is seen that even in $\mathrm{Fe}_{2} \mathrm{CrO}_{4}$ sample, which has a spinel structure, and which has both the cations from $3 \mathrm{~d}$-series having significant magnetic moment, there is no hyperfine magnetic field $\mathrm{B}_{\mathrm{hf}}$. Thus at nanosize, the correlation of saturation magnetization and hyperfine magnetic field might break down. The Mössbauer parameters of all samples are similar and no appreciable change was seen in the samples having particles size less than 11-12 nm or bigger than this size.

\section{Conclusions}

1. Non-stoichiometric iron chromite $\mathrm{Fe}_{2} \mathrm{CrO}_{4}$ shares the crystal structure of pure spinel, and hence, the magnetic interactions go via super-exchange interactions as it happen in spinel structure.

2. In the size range $6-35 \mathrm{~nm}$, there is clear magnetic ordering shown by significantly large saturation magnetization and Stype shape of M-H curve.

3. None of the $\mathrm{CrF}$ samples showed any hyperfine splitting even down to $16 \mathrm{~K}$. It has been observed that at size around 11-12 $\mathrm{nm}$ there is drastic change in the magnetic properties but no change in hyperfine interactions.

4. The samples having particles around $11 \mathrm{~nm}$ shows very high strain and restricts formation of magnetic domains in the sample of particle size below $11 \mathrm{~nm}$. This investigation opens up new field to investigate other physical properties which varies similar and/or dissimilar to magnetic properties.

\section{Acknowledgement}

Author would like to sincerely acknowledge the help provided by Prof H. C. Verma in recording Mössbauer spectra and for valuable discussions.

\section{References}

Chinnasamy C. N., Narayanasamy A. N Ponpandian, K Chattopadhyay, H Guérault and J-M Greneche, 2000. Magnetic properties of nanostructured ferrimagnetic zinc ferrite. J. Phys. Condens. Matter, Vol.12, pp. 7795-7806. 
Hamdeh H.H., Ho J.C., Oliver S. A. willey R. J., Oliveri G., Busca G., 1997. Magnetic properties of partially-inverted zinc ferrite aerogel powders. J. Appl. Phys. Vol. 81, pp1851-1857

Ho J.C., Hamdeh H.H., Chen Y.Y. Lin S. H., Yao Y. D., Willey R. J., Oliver S. A., 1995. Low-temperature calorimetric properties of zinc ferrite nanoparticles. Phys. Rev. B. Vol. 52, pp.10122- 10126.

Jiang J. S., Yang X. L., Gao L. Guo J. K., Jiang . Z., 1999. Synthesis and characterization of nanocrystalline zinc ferrite Nanostructured Materials, Vol. 12, pp. 143- 146

Kundu A., Upadhyay C., Verma H. C., 2003a. Magnetic properties of a partially inverted zinc ferrite synthesized by a new coprecipitation technique using urea. Phys. Letter A,Vol. 311, pp. 410-417

Kundu A., Anand S., and Verma H. C., 2003b. A citrate process to synthesize nanocrystalline zinc ferrite from 7 to $23 \mathrm{~nm}$ crystallite size. Powder Technol. Vol.132, pp. 131-138

Oliver S.A., Hamdeh H.H., Ho J.C., 1999. Localized spin canting in partially inverted $\mathrm{ZnFe}_{2} \mathrm{O}_{4}$ fine powders. Phys. Rev. B, Vol. 60, pp. 3400-3407.

Pandey B., Unpublished Ph.D. Thesis, Indian Institute of Technology, Kanpur, 2007

Robbins M.,Wertheim G.K., Sherwood R.C., Buchanan D.N.E. 1971. Magnetic properties and site distributions in the system $\mathrm{FeCr}_{2} \mathrm{O}_{4}-\mathrm{Fe}_{3} \mathrm{O}_{4}\left(\mathrm{Fe}^{2}+\mathrm{Cr}_{2-x} \mathrm{Fe}_{x}^{3+} \mathrm{O}_{4}\right)$. J. Phys. Chem. Solids. Vol.32, pp. 717- 729.

Roy M.K., Haldar B. and Verma H. C., 2006. Characteristic length scales of nanosize zinc ferrite. Nanotechnology Vol. 17, pp. 232-237.

Shenoy S.D., Joy P.A., Anantharaman M.R., 2004. Effect of mechanical milling on the structural, magnetic and dielectric properties of coprecipitated ultrafine zinc ferrite. J. Magn. Magn.Mater, Vol. 269, pp. 217-227

Tada M., Hatanaka S., Sanbonsugi H. Matsushita N., Abe M., 2003. Method for synthesizing ferrite nanoparticles $\sim 30 \mathrm{~nm}$ in diameter on neutral $\mathrm{pH}$ condition for biomedical applications. J. Appl. Phys. Vol. 93, pp.7566-7568

Williamson G.K. and Hall W.H, 1953. X-ray line broadening from filed Aluminium and Wolform. Acta. Metal. Vol.1, pp. 22-31.

Zhou Z. H., Xue J. M., Chan H. S. O. Wang J., 2001. Transparent magnetic composites of $\mathrm{ZnFe}_{2} \mathrm{O}_{4}$ nanoparticles in silica. J. Appl. Phys. Vol.90, pp. 4169-4174.

\section{Biographical notes}

Dr. Brajesh Pandey completed his doctoral degree from Indian Institute of Technology, Kanpur, India in 2008. His area of research includes defect production in metallic alloy system using mechanical deformation, nanoparticle oxides and geological boundaries.

Received September 2010

Accepted November 2010

Final acceptance in revised form November 2010 